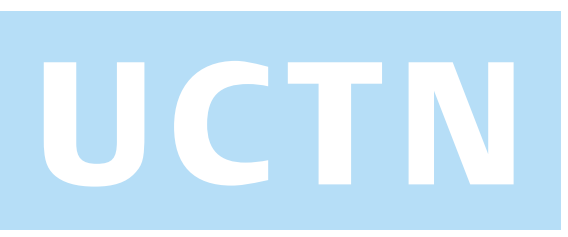

Routine examination of the terminal ileum during colonoscopy can provide useful information [1], but remains optional depending upon various factors including the discretion of the endoscopist and difficulty with other aspects of examination. We encountered a case where ileoscopy and biopsy resulted in a prompt diagnosis of coeliac disease.

A 57-year-old farmer was referred with a 3-month history of griping lower abdominal pain associated with alternating loose stools and constipation. There was no weight loss. Clinical examination including rigid sigmoidoscopy showed normal findings except for a reducible left inguinal hernia. He was mildly anaemic with a haemoglobin level of $11.0 \mathrm{~g} / \mathrm{dl}$ $(13-15)$ with a mean cell volume of $79 \mathrm{fl}$ (76-96).

Colonoscopy showed normal findings, but at ileoscopy adherent white fluid material coating the terminal ileum was observed. Biopsies showed an intra-epithelial lymphocyte infiltrate but normal villous architecture (Figure 1). Antiendomysial antibodies were then checked and these were strongly positive to a titre of $1: 300$. A diagnosis of coeliac disease was made and his symptoms and anaemia improved in less than 3 months on a gluten-free diet.

\title{
Ileocolonoscopic Diagnosis of Coeliac Disease
}

Ileal examination during colonoscopy is often easily performed, with a success rate of $70-90 \%$ [2], depending on the experience of the colonoscopist, and usually takes 3-4 minutes [3]. To our knowledge this is the first report of identification of coeliac disease at ileal examination during a routine colonoscopy. Ileal examination has been reported as giving useful diagnostic information in up to $18 \%$ of the non-HIV-positive patient population presenting with diarrhoea, as opposed to $2.7 \%$ in asymptomatic patients $[4,5]$. We do not consider the endoscopic appearance in our patient to be pathognomonic, but the histological appearance was interpreted as suggestive of coeliac disease. We agree with the recommendation that ileal intubation and biopsy be attempted in all cases of colonoscopy if the patient has diarrhoea.

\section{Acknowledgement}

We thank Dr M. Atkinson, consultant pathologist, for histological expertise.

\section{N. Sundar, A. Mukhtar, I. A. Finnie Department of Gastroenterology, Glan Clwyd Hospital, Bodelwyddan, Denbighshire, Wales, UK}

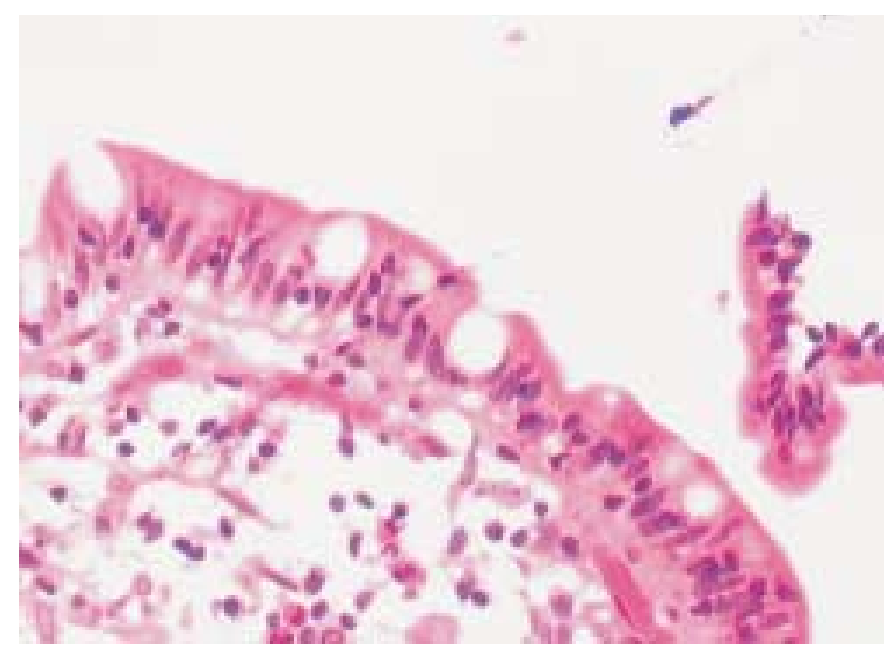

Figure 1 Terminal ileal biopsy (haematoxylin and eosin; $\times 300$ ). The villous pattern is normal, but when viewed at high power the intraepithelial lymphocte: enterocyte ratio is approximately $1: 1$. The pathological report recommended that coeliac disease should be considered.

\section{References}

${ }^{1}$ Borsch G, Schmidt G. Endoscopy of the terminal ileum. Dis Colon Rectum 1985; 28: 499 - 501

2 Marshall JB, Barthel JS. The frequency of total colonoscopy and terminal ileal intubation in the $1990 \mathrm{~s}$. Gastrointest Endosc 1993; 39: 518 - 520

${ }^{3}$ Kundrotas LW, Clement DJ, Craig M et al. A prospective evaluation of successful terminal ileum intubation during routine colonoscopy. Gastrointest Endosc 1994; 40: $544-546$

${ }^{4}$ Zwas FR, Bonheim NA, Berken CA et al. Diagnostic yield of routine ileoscopy. Am J Gastroenterol 1995; 90: 1441 1443

${ }^{5}$ Shah RJ, Fenoglio-Preiser C, Bleau BL et al. Usefulness of colonoscopy with biopsy in evaluation of patients with chronic diarrhoea. Am J Gastroenterol 2001; 96: 1091 - 1095

\section{Corresponding Author}

\section{A. Finnie, M.D.}

Department of Gastroenterology

Glan Clwyd Hospital

Bodelwyddan

Denbighshire, LL18 5UJ

Wales

United Kingdom

Fax: + 44-1745-534135

E-mail: Jo.Barlow@cd-tr.wales.nhs.uk 